political problem of a somewhat complex kind. $\mathrm{He}$ is essential to the development of the country and the production of revenue; but his secret societies, and not the law of the land, receive his homage. Mr. Smyth never tires of contrasting the dirty, greedy and illmannered Chinaman with the dainty, generous, and courteous Siamese or Shan; only one of the despised race finds favour in his pages-a boatbuilder who created the very clever little vessel in which the voyage to Chantabun was made. This voyage is the subject of several chapters describing visits to various places in Siamese Cambodia, including the famous ruby and sapphire workings east of Chantabun.

Appendices to the number of eighteen give a great deal of interesting information on many matters, economic, scientific, resthetic, and archrological. The peculiar tides of the Gulf of Siam are discussed, and the singular musical instruments of the country described

\section{THE NATURE OF THE ANTAGONISM BETWEEN TOXINS AND ANTITOXINS.}

THE subject of toxins and antitoxins, though still in its infancy, is one which possesses considerable importance not only to the scientific world, but also to all members of the community. In the cases of snake poisoning, and diphtheria especially, the curative results that follow the administration of antitoxic serum are most marked, and it is in connection with these two conditions that the subject bas been principally worked out. Important and interesting as these results are, foreshadowing as they do a new method of therapentics in many other diseases, there are still two fundamental questions which have hitherto remained unanswered. The first of these is, What is the nature of the substances in question? The second is, What is the nature of the antagonism between them?

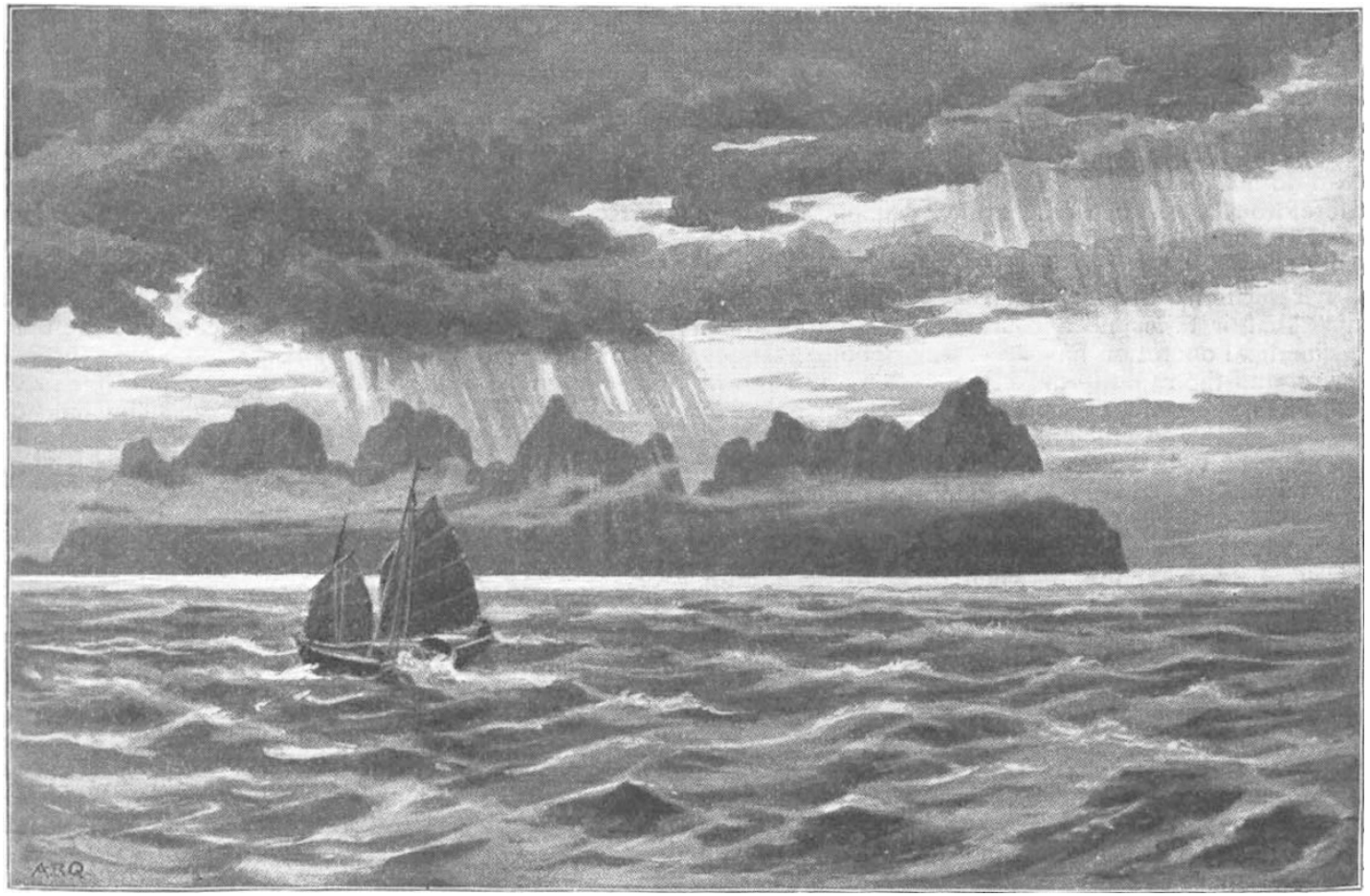

Off Sanı Roi Yawt: the three hundred peaks.

at length, while some Siamese airs are also reproduced. One of the most interesting of the appendices compares the naval architecture of modern Siam with that of ancient Rome and Egypt. The resemblance of the Siamese and Egyptian vessels, both canoes and sailingboats, is very remarkable, not only in build but in the manner of working.

Mr. Smyth has illustrated his text throughout with his own clear and characteristic sketches. He comments strongly, but not too strongly, on the unsatisfactory plan of allowing an artist at home, who never saw the scenes himself, to "finish" the sketches of a traveller. Possibly first-rate photographs would be more valuable than the sketches ; but they are far preferable to the inferior photographic work too often brought home by amateurs from tropical countries. The specimens of these sketches reproduced will show their interest.

$$
\text { HuGH ROBERT MILL. }
$$

In a paper recently presented to the Royal Society (June 9), Dr. C. J. Martin and Dr. T. Cherry, of Melbourne, have given a very definite and conclusive answer to the second of these questions. The first, the nature of the substances themselves, still demands fuller investigation. The authors show, however, in confirmation of work previously performed by one of them (C. J. M.), and independently by Dr. T. G. Brodie, that the materials in question have a high molecular weight, and fall into the category of proteids or proteid-like substances. A method of separating substances of large from those of smaller molecular size in a solution containing both, consists in filtering it under high pressure through a film of gelatin supported in the wall of a Pasteur-Chamberland filter. The antitoxin of diphtheria does not pass through such a filter; it is probably a globulin, or at any rate its molecular size is of the same order. When antitoxic serum is filtered in the manner

NO. I 50 I, VOL. 58] 
just indicated, the whole of the proteids, and together with them all antitoxic virtue, is absent from the filtrate. Toxin, on the other hand, the molecular size of which is of the albumose order, is not held back by the filter. Corresponding results are obtained with the toxin and antitoxin of snake venom.

Coming now to the second question, the nature of the antagonism between these substances, we find that it is one on which a difference of opinion has hitherto been held. Behring, Ehrlich, Kanthack and Brodie maintain that the antagonism is of a chemical nature, and that the antitoxin neutralises the toxin much in the same way that an alkali neutralises an acid. Buchner, Calmette, Metchnikoff, and others, on the other hand, regard the action as an indirect one, operating in some way through the medium of the cells of the organism. The work on which such an assertion rests may be instanced by a typical experiment of Calmette's on cobra poison. The venom is not attenuated by heating its solutions to $68^{\circ} \mathrm{C}$. for ten minutes; the antitoxin is, however, completely destroyed by this treatment. Mixtures of cobra toxin and antitoxin, which produced no symptoms when injected into rabbits, killed similar rabbits in a few hours if, after the mixture had remained in contact for ten minutes, it were heated to $68^{\circ} \mathrm{C}$. for another ten minutes before injecting; hence the conclusion that the toxin and antitoxin do not interact in vitro, but only in corpore, and therefore that the action cannot be explained as a simple chemical operation between the two.

Such an experiment is not, however, conclusive ; it can be easily repeated with the same result, but the source of fallacy is that it takes no account of the factor-time. Every chemical operation has a certain definite velocity coefficient, and the rapidity of action under any circumstances when the reacting compounds are in solution depends upon this coefficient, and also upon the product of the active masses of the compounds present. Temperature will also exercise an important influence.

Remembering the high molecular weight of both toxin and antitoxin, one would a priori expect the velocity coefficient of any reaction between them to be a high one, and in addition the solution would contain relatively few molecules; so it is not surprising that any chemical opcration should occupy a very appreciable time. If the two substances are left in contact for more than Calmette's ten minutes, the substances completely neutralise each other in ritro.

The following table gives a summary of Martin and other, with proportion of active masses constant. On reading any vertical line, the influence of varying proportions of active masses with time of operation constant is indicated. The thick line separates off the fatal results from those in which the rabbits lived. All other factors were kept constant. The solutions were mixed in the varying proportions, and stood at laboratory temperature $\left(20^{2}-23^{3} \mathrm{C}\right.$.). At stated intervals, by a stop-watch, portions were pipetted off, and the reaction terminated by rapidly raising the temperature to $68^{\circ} \mathrm{C}$. in a water bath. They were kept at this temperature for ten minutes; cooled, and kept for injection.

Fxactly corresponding results were obtained with diphtheria toxin and antitoxin; and we may conclude by quoting an experiment with these substances, in which a different modus operandi was adopted. Similar experiments have been recently performed by Brodie, and published in his Arris and Gale lectures; his results completely coincide with those of Martin and Cherry.

A solution of toxin containing cight fatal doses per kilogram of guinea-pig in each c.c. was mixed with sufficient antitoxin to more than completcly neutralise all the toxin. This mixture was allowed to remain in contact at $30^{3} \mathrm{C}$. for two hours, and then filtered through the gelatin filter. Varying quantities of the filtrate were injected into guinea-pigs up to nearly 4 c.c. per kilogram of body-weight ; that is, a quantity originally containing thirty-two fatal doses. The filtrate was quite innocent. The guinea-pigs suffered no inconvenience, and gained weight while under observation in small cages. The injections produced no local œdema.

If the toxin had remained unaffected beside the anti. toxin, there was nothing to prevent it passing through the filter in virtue of its relatively small molecular size. As, however, it did not do so, we can only conclude that it had entered into some sort of chemical relationship with the relatively large molecules of the antitoxin during their sojourn together prior to filtration.

IV. D. H.

\section{A MINISTER OF EDUCATION AT LAST.}

THE Duke of Devonshire made a most important speech on Monday in introducing a new IBill relating to Secondary Education.

The Bill really seeks to reconstruct the whole of our haphazard organisation dealing with Education, Science and Art ; whether the recommendation will do harm or

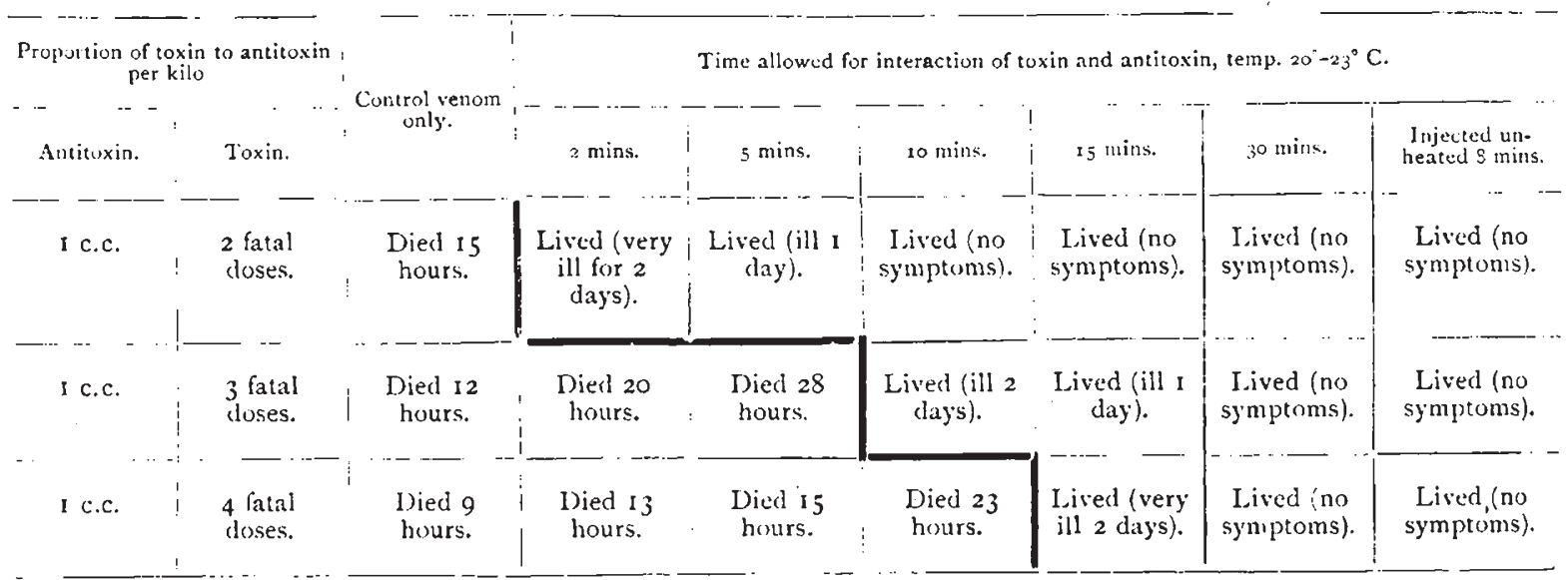

Cherry's principal experiments with snake venom. On reading along any horizontal line will be seen the influence upon the result of the time during which the toxin and antitoxin were allowed to operate upon each NO. I jOI VOL. 58] grood depends upon the reconstructors, and who they are does not appear. It should, howerer, be a matter of congratulation that the lamentable condition of our present want of system, which has been known to educa- 